\title{
MOBILE TECHNOLOGY TO PROMOTE EDUCATION 4.0 IN VIETNAM
}

\author{
Loc My Thi Nguyen', \\ Tuong Sy Hoang ${ }^{2,+}$
}

\section{Article History}

Received: 11 September 2020

Accepted: 20 November 2020

Published: 30 December 2020

\section{Keywords}

Mobile technology, education 4.0, higher education, students

\author{
${ }^{1}$ VNU University of Education, Vietnam; \\ ${ }^{2}$ Vietnam Academy of Cryptography Techniques, Vietnam \\ ${ }^{+}$Corresponding author • Email: hoangtuong@gmail.com
}

\section{INTRODUCTION}

Nowadays, the development of Information and Communication Technology (ICT) not only has an impact on the industrial sector but also has a strong impact on education and training. As technology grows more and more, the use of gadgets for example smart devices is increasingly popular due to the breakthrough development of technology. Mobile learning as an educational activity makes sense only when the technology in use is fully mobile and when the users of the technology are also mobile while they learn. These observations emphasise the mobility of learning and the significance of the term "mobile learning" (Traxler, 2007). According to Crescent, Mary Louise, Lee, Doris (2011), learners can study anywhere and anytime just through smart devices. Therefore, mobile learning has great potential to support teaching and learning environment in the today context. This article delves into theoretical and practical view of learning on mobile devices of students in higher education 4.0 of Vietnam and review some previous research to connect the reality and prospects of mobile learning with teaching and learning in higher education environments 4.0.

\section{LITERATURE REVIEW}

\subsection{Overview of mobile learning}

In recent time, e-learning method has become the mainstream way to help students participate in a mobile learning environment. It is predicted that in the near future, with an explosion of new smart devices and technologies like smart phones and laptops, these devices will exceed the number of personal computers. Pink Wart et al (2004) define e-learning as a learning method supported by digital tools and multimedia in the form of digital signals. Many technology and education experts consider mobile learning as the inheritance of e-learning method.

Figure 1 illustrates three definitions of mobile learning in Education 4.0. Elements of mobility can be divided into three important areas: technology mobility, learner mobility and learning mobility. Successful application of tertiary teaching process depends on the meaning of the word mobile as it is used in the higher education context. Therefore, these three elements are interdependent and are equally important through making mobile devices viable as devices 


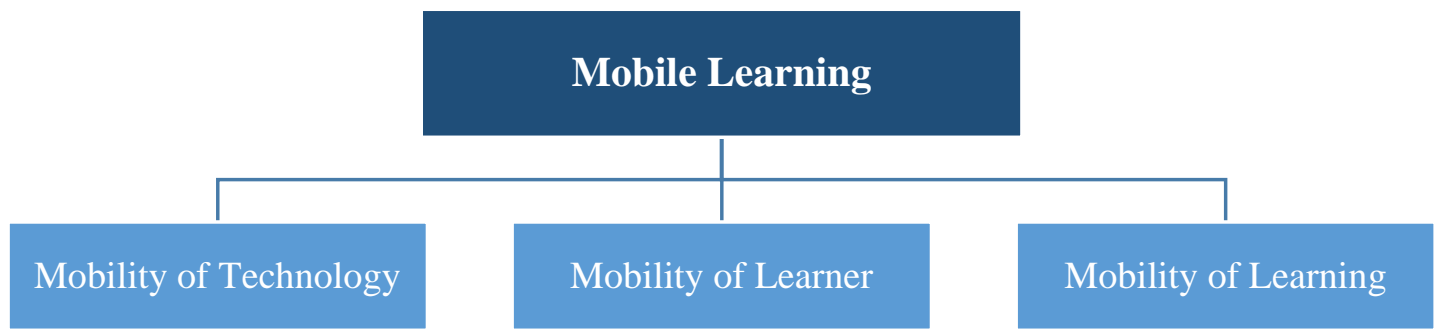

Figure 1. Elements of mobile learning

used to deliver teaching content at high education. Designing and developing mobile learning apps is not an easy task; it requires knowledge of programming, of graphic design, lecture design and aggregate of content. According to Saville S., \& Attewell J. (2004), the use of mobile devices for learning increases students' motivation helps improve organizational skills and encourages responsibility, supporting both independence and collaboration in learning. It acts as reference tools, tracks student progress and provides tools to evaluate the learning process for students. As a result, some higher education institutions, research institutes or schools have begun to build mobile applications to serve their students according to their curriculum and learners' need. Many experts conducted research on mobile learning environments many years ago. Kulkuska-Hulme et al. (2009) have shown through their studies that mobile learning is possible to achieve goals that other learning systems do not meet like being the optimal solution for blend learning, providing a collection of options to suit individual learning needs instead of everyone. It doesn't simply provide teaching materials that can also be used for creative learning, collaboration, and communication. Some of mobile learning projects have been developed by experts around the world including "bubble sort", "binary search", mobile DNA and Mobile Mathematic applications. Recently, experts focus on the field of technology assistance for education.

Mobile learning became part of educational technology and can be used in a variety of disciplines. McGrane and Armadillo (2011) through their research also consider that mobile training is an inevitable trend. Electronic intelligent devices have been widely used in creating digital learning resources for training activities. According to Graham (2020) educators are moving gradually from preventing students from using smartphone in the classroom to using learning content that can use the smartphone as a learning tool. The use of mobile devices in combination with the web has created a new trend in university training: online training and distance learning. Laru and Järvelä, S. (2008) believe that using web technology in combination with mobile devices will create online learning and knowledge sharing communities. In another study, Cavus and Al-Momani (2011) appreciated the role of mobile devices and smart electronics. In particular, mobile device systems will create a flexible training system for universities.

There have been many studies on the influences and factors affecting the use of electronic devices for students' learning. According to research results of Chen and Danyelle (2013), it is shown that the rate of smartphone use among students is increasing. Many students bring their electronic devices to university (because of outstanding features and superior, compact design such as smartphones and tablets, laptops). In which the proportion of students using laptops (85\%) is used as the most important device for their academic success, while electronic devices such as tablets (45\%), smart phone (37\%) and e-reader (31\%) are significantly increasing year by year. The study also found that many students said they wanted to be able to access learning resources on their mobile devices. The report indicated that $67 \%$ of students' smartphones and tablets are being used for academic purposes in higher education.

\subsection{Trend of mobile learning in the world and Vietnam}

The development of devices using digital technology including smart mobile devices in the past two decades has opened up many opportunities for distance education and online training. The United Nations Educational Scientific and Cultural Organization (UNESCO) has recommended countries to adopt policies to promote the construction of information technology infrastructure and telecommunication equipment to expand learning online. In the U.K., Denmark and the Netherlands, policy makers have launched a number of initiatives to promote learning on mobile devices. The U.K. government has initiated mobile learning programs for primary and secondary education and partnered with telecom companies to provide mobile technology to college students. The Netherlands does not have a national strategy for online learning on mobile devices, but it has a lot of efforts to develop mobile learning in primary, secondary and high education. The popularization of mobile learning has also been developed in Russia and Ukraine. Ukraine has initiatives for students to get used to learning on mobile devices in schools. Japan and South 
Korea have implemented national-scale mobile learning projects with a policy to facilitate the use of mobile devices in education. Smart education promotion strategy in Korea has integrated mobile devices into everyday school environment to prepare students for the future learning environment.

Mobile learning is on a platform that organizes, shares and stores information and knowledge in a very systematic way, unlike a traditional classroom that forces everyone to learn at the same time with the same speed. Besides, it is the transparency and standardization of lecture quality when teaching contents are built and posted on the system. Since then, teachers can continuously improve the quality; the educational institutions also make it easier to manage and ensure quality. In addition, learning on mobile devices also helps learners save money, time and improve their accessibility to knowledge. For educational institutions, the cost of managing and organizing classes is also reduced significantly. Learners in remote and rural areas can participate in classes and exploit learning data on mobile devices.

Vietnam now has more than 20 million students, 2 million teachers at all levels, and the popularity of the Internet and the high level of mobile device use show the need for attention to mobile learning; especially, in time of difficulties and challenges from natural disasters and epidemics such as COVID-19. In order for the deployment of teaching and learning on mobile devices to be synchronized in the system, we also need to change the way of seeing, evaluating, and changing the process of education and training management. Besides, a number of barriers to this learning method must soon be overcome, from synchronous information technology infrastructure to have technical support from stakeholders. Teachers and learners must be fostered with enough skills to use information technology devices to be able to use the learning method on mobile devices as an auxiliary tool, considering it as a teaching method and primary learning has replaced the traditional teaching and learning methods that are being applied in today's educational institutions.

\subsection{Education 4.0 for high education}

Education 4.0 in the today context is the application of digital technology. One of the Vietnamese government's aspirations is to train a technology knowledge generation for the future. Therefore, all Vietnamese universities must prepare to adapt and change their training programs to help graduate students find new jobs arising from the 4.0 revolution. Educators also have to keep pace with the speed of technology development. In addition, within the framework of education 4.0, the challenges of the 4th industrial revolution (IR4.0) have been solved with regard to the policy "Fundamental and comprehensive reform of Vietnamese education towards standardization, modernization, socialization, democratization and international integration". Figure 2 illustrates the stages that education has evolved over the past time. Development is divided into 4 phases of educational transformation. This chart shows how things have been transformed from education 1.0 to the current education 4.0 model. There are changes in reading and learning habits that need educators' attention to be able to introduce new pedagogical methods as described for these 4 phases. Moreover, the rapid development of Industry 4.0 also makes a leap from education 2.0 to education $3.0 / 4.0$.

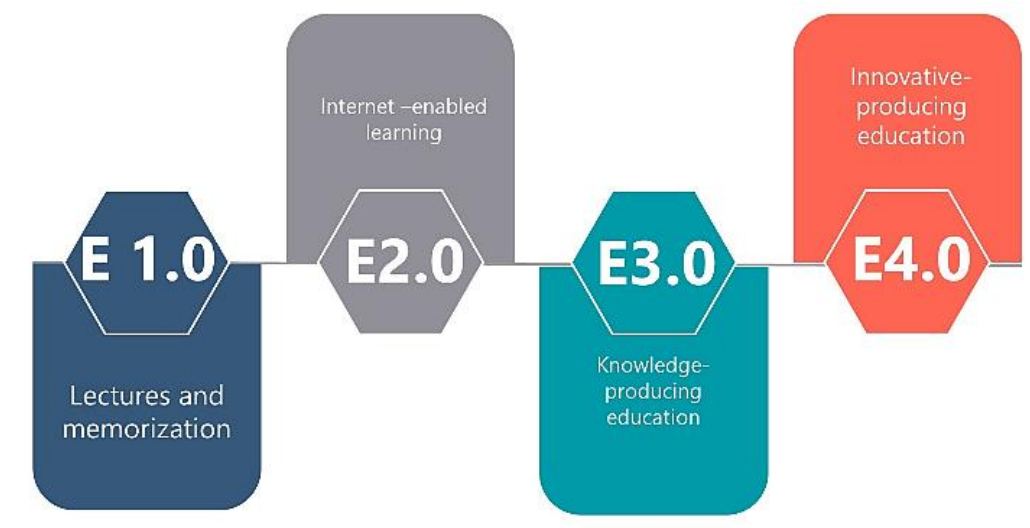

Figure 2. The evolution of education

Digital technology can provide a platform to support new ways of learning to engage students, increase school revenue, and help schools cut operating costs and create a reputation as well as helping to promote brands for universities. From lectures built in video files allowing online access to course materials, students can participate in the classroom anytime anywhere through technology devices. In the age of smartphone classes, robotic help, and online exams, it is not hard to imagine what is education in the context of industry 4.0 can do for us. Education in the 
context of industry 4.0 can be seen as a phenomenon of digital application in everyday life. Universities in Vietnam today have to deal with these challenges by properly training and restructuring training models that may have to identify some changes in the higher education system suitable for the future.

There is a need to create more viable and flexible learning environments for students and empower teachers to deliver more content rich and creative lessons, whether in traditional or traditional forms learn online and make sure to get more feedback from learners as well as better monitor the training process. Therefore, Vietnamese universities need to re-plan virtualized training models to provide convenience for learners in the digital age. This is where the rules that bring together community, cross-industry and core values come into play.

\section{RESEARCH MOTHODS AND RESULTS}

\subsection{Research methods}

These are preliminary studies and the beginning of the mobile learning application development and construction process. To develop mobile learning applications, the authors use ADDIE model presented in Figure 3. This model includes five processes (1) reviewing and analyzing students' use of mobile phones; (2) mobile learning app design process; (3) mobile learning app development process; (4) implementing mobile learning modules; (5) learning application assessment process mobile.

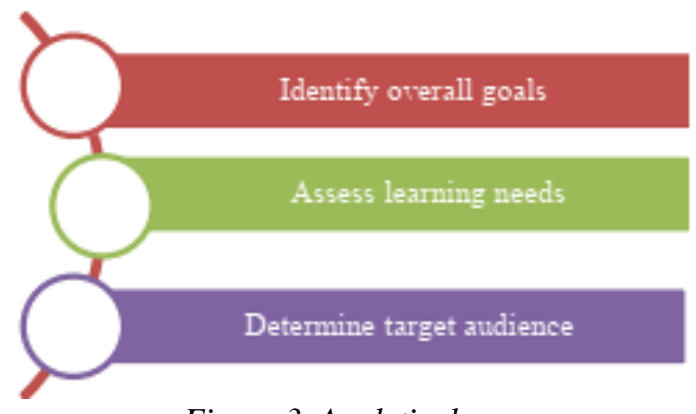

Figure 3. Analytical process

The analysis of mobile phone use in the research is very important because the results of the analysis will be used in evaluating and building a mobile learning environment for students. The purpose of the study is to identify the theoretical bases and practices of students' mobile learning from perspectives such as the use of smartphones and mobile devices for learning, the types of mobile devices used to learn as well as the time students spend learning on their smartphone and mobile device. The study also focuses on re-describing the studies of some domestic and foreign authors related to the assessment of the practical basis of mobile learning as well as the prospects of teaching and learning in higher education in RV 4.0. The study aims to answer the following research questions:

- Do students use smartphones and mobile devices for the learning process?

- What types of smartphones and mobile devices do students use to participate in the learning process?

- How much time do students spend using smartphones and mobile devices in their studies?

\subsection{Participants}

The research was carried out on 450 university students studying Information Security majors at Academy of Cryptographic Techniques, People's Security Academy, Institute of Military Technology in Vietnam. The students questioned are students who are regularly using at least one mobile device in learning. The research is surveyed on students who are engaged in learning in traditional classes. The results obtained through the experiment have provided valuable information for research content related to the theoretical and practical basis of using mobile technology in the student learning process. Among the students interviewed, there were 380 female students $(84 \%)$ and 70 male students (16\%). In general, there are two different age groups interviewed, including 420 people (93\%) of 19-20 years old and only 30 people $(0,7 \%)$ of 20-22 years old. All students participating in the research process are students who are studying Information Security majors - Academy of Cryptographic Techniques, People's Security Academy, Institute of Military Technology in Vietnam.

\subsection{Findings}

All 450 students participating in the research process were surveyed through questionnaires. Then, data were collected, synthesized and analyzed using SPSS 21.0 software. The use of smartphones and mobile devices for the learning process is presented in Figure 4. Results showed that most of the students surveyed (97.7\%) used smartphones and mobile devices for learning. 


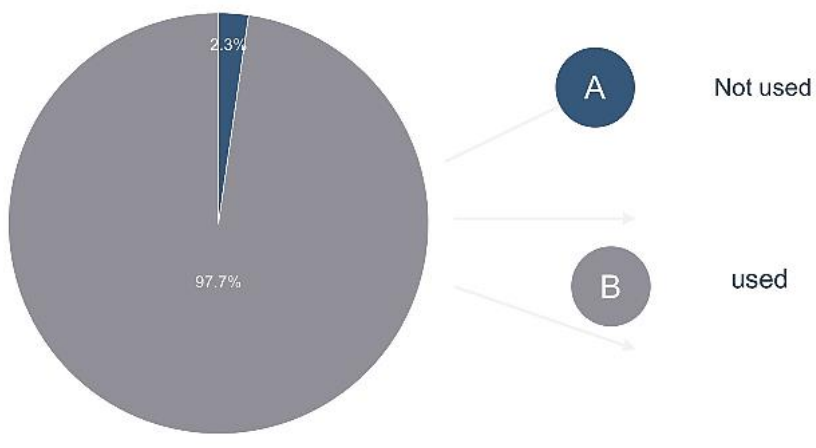

Figure 4. Proportion of using telephones for learning

The study results also showed that only $2.3 \%$ of the students participating in the survey did not use mobile devices for study. This result shows that most of the students use mobile devices, especially for study and research purposes.

Types of smartphones and mobile devices used for mobile learning

Mobile phones, tablets, and e-readers are the types of dynamic devices listed in the questionnaire. Figure 5 shows the types of portable devices students typically use for their studies.

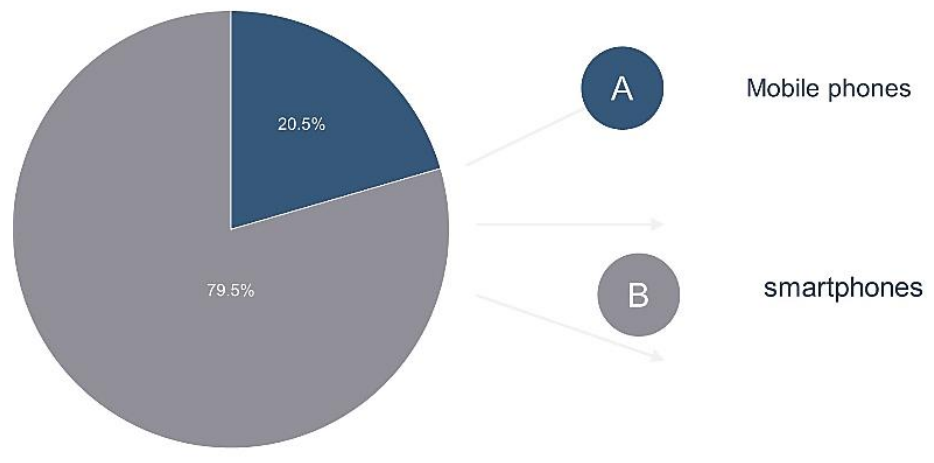

Figure 5. Types of smartphones and mobile devices used for mobile learning

The most popular smart device used by students for study is smartphone (79.5\%) while the second most popular device that students use to study is mobile phone (20.5\%). The study results can confirm that most students have smartphones, and they prefer to use smartphones for academic purposes.

Time using smartphones and mobile devices for mobile learning

Figure 6 describes total time in a day that students use a mobile device for learning. Most of the students surveyed $(52.3 \%)$ spend at least 1 hour or more, but less than 3 hours per day using a mobile device for studying purposes. A total of $27.3 \%$ of the students questioned have used mobile devices for 3 hours or more, but less than 7 hours per day for studying. While $18.2 \%$ of students surveyed said that they spend less than 1 hour per day for studying. The study results also showed that only $2,3 \%$ of the students surveyed do not spend any time using mobile devices for study.

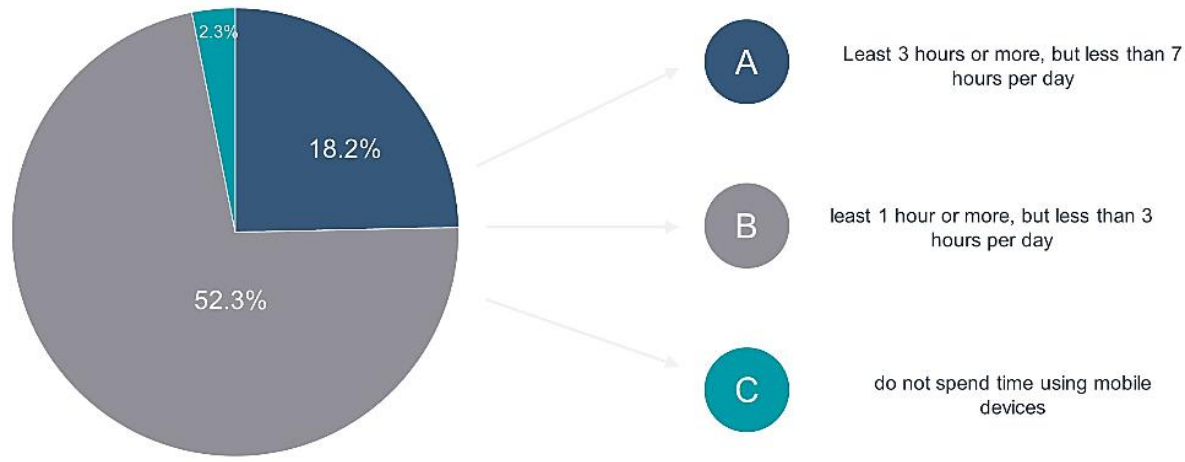

Figure 6. Time spent using mobile devices for learning 
Survey results show that most of the students surveyed use mobile devices for learning purposes and that most of the day students spend time using mobile devices for study only. There is only one student who does not spend his time using a mobile device for studying purposes.

\section{DISCUSSION AND CONCLUSION}

Regarding the adoption of technology by students, students' use mobile learning for education in the IR 4.0, the study provides theoretical and practical basis of students' using smartphones and mobile devices for learning and shows that this use is positive. In general, most students believe that mobile devices can help them in their study. This finding is in line with results obtained from previous studies by other authors on the positive effects of mobile learning behaviors is possible.

However, the future of mobile learning depends on the determination of the Ministry of Education and Training as well as of society acceptance. In fact, developing world learners have a huge demand for mobile learning. Mobile learning makes learning mobile, and learners don’t need to go to the classroom.

\section{REFERENCES}

Caves, N. \& Al-Momani, M. M. (2011). Mobile system for flexible education. Procedia Computer Science, 3, 1475-1479. https://doi.org/10.1016/j.procs.2011.01.034

Chen, B. \& Danyelle's, A. (2013). Exploring students' mobile learning practices in higher education. Retrieved from https://er.educause.edu/articles/2013/10/exploring-students-mobile-learning-practices-in-higher-education

Crescente, M. L., \& Lee, D. (2011). Critical issues of M-Learning: design models, adoption processes, and future trends. Journal of the Chinese Institute of Industrial Engineers, 28(2), 111-123. https://doi.org/10.1080/ 10170669.2010.548856

European Commission. (2017). Education 4.0 Mobile Learning. Luxembourg: Office for Official Publications of the European Communities.

Graham, E. (2020). Using smartphones in the classroom. Retrieved from http://www.nea.org/tools/56274.htm

Kukulska-Hulme, A. (2009). Will mobile learning change language learning? Recall, 21(2), 157-165. http://dx.doi.org/10.1017/S0958344009000202

Kukulska-Hulme, A. (2013). Re-skilling language learners for a mobile world. The International Research Foundation for English Language Education (TIRF), Monterey, USA. https://www.tirfonline.org/publications/ mobile-assisted-language-learning/re-skilling-language-learners-for-a-mobile-world

Kukulska-Hulme, A., \& Shield, L. (2008). An overview of mobile assisted language learning: From content delivery to supported collaboration and interaction. Recall, 20(3), 271-289. https://doi.org/10.1017/S0958344008000335

LaRue, J. \& Järvelä, S. (2008). Using web 2.0 software and mobile devices for creating shared understanding among virtual learning communities. Fifth IEEE International Conference on Wireless, Mobile, and Ubiquitous Technology in Education.

Pinkwart, N., Jansen, M., Olinger, M., Korchounova, L., \& Hoppe, U. (2004). Partial generation of contextualized metadata in a collaborative modeling environment. In L. Arroyo and C. Tasso (Eds.), Workshop Proceedings of the $3^{\text {rd }}$ International Conference on Adaptive Hypermedia. Technical University, Eindhoven (NL), 372-376.

Saville, S., \& Attewell, J. (2004). Mobile learning and social inclusion: focusing on learners and learning. In Learning with Mobile Devices: Research and Development. LSDA .UK.

Traxler, J. (2007). Defining, Discussing and Evaluating Mobile Learning: The moving finger writes and having writ... The International Review of Research in Open and Distributed Learning, 8(2). https://doi.org/10.19173/ irrodl.v8i2.346 